\title{
The state of lipid exchange and thrombotic link of hemostasis in patients with chronic non-specific inflammatory diseases of genitals
}

Irina Sokolovska ${ }^{\mathrm{a}^{*}}$, Nadezhda Maryukhnich ${ }^{\mathrm{b}}$, Valentyna Zarytska ${ }^{\mathrm{c}}$, Olena Kyrpychenko ${ }^{\mathrm{c}}$. Valentina Nechiporenko $^{\mathrm{d}}$, Olena Pozdnyakova ${ }^{\mathrm{d}}$, Natalia Gordiyenko ${ }^{\mathrm{d}}$, Victor Tsymbal ${ }^{\mathrm{e}}$ Department of Hygiene, Zaporizhzhya State Medical University, avenue Mayakovsky 26, Zaporizhzhya 69035, Ukraine

Zaporizhzhya State Medical University ${ }^{a}$, Zaporizhzhya National Technical University ${ }^{b}$, Classic Private University ${ }^{c}$, Khorticky National Academy $^{d}$, Zaporizhzhya National University ${ }^{e}$

irinasokol10@meta.ua

Keywords: lipids, hemostasis, reactivity, chronic non-specific inflammatory diseases of genitals. It has been stated that changes of lipid exchange and increasing of lipid peroxidation are accompanied by the inflammatory process, which show the increase of proatherogenic blood characteristics. In patients with chronic non-specific inflammatory diseases of genitals disorders of phagocytosis mechanisms, increasing of autointoxication and reaction of hypersensitivity of immediate type are revealed after full blood count index. On the basis of analyses results one can conclude that the increase of atherogenic properties of blood plasma in patients with chronic non-specific inflammatory diseases of genitals took place in accordance with vascular endothelium damage. The article is the first to show the effectiveness of complex treatment of different atherosclerotic pathogenesis links by means of correction of proatherogenic lipid fractions and antioxidative complexes.

\section{Introduction}

Lipoproteins are complex particles that have a central hydrophobic core of non-polar lipids, primarily cholesterol esters and triglycerides. This hydrophobic core is surrounded by a hydrophilic membrane consisting of phospholipids, free cholesterol, and apolipoproteins (Figure 1).

Plasma lipoproteins are divided into

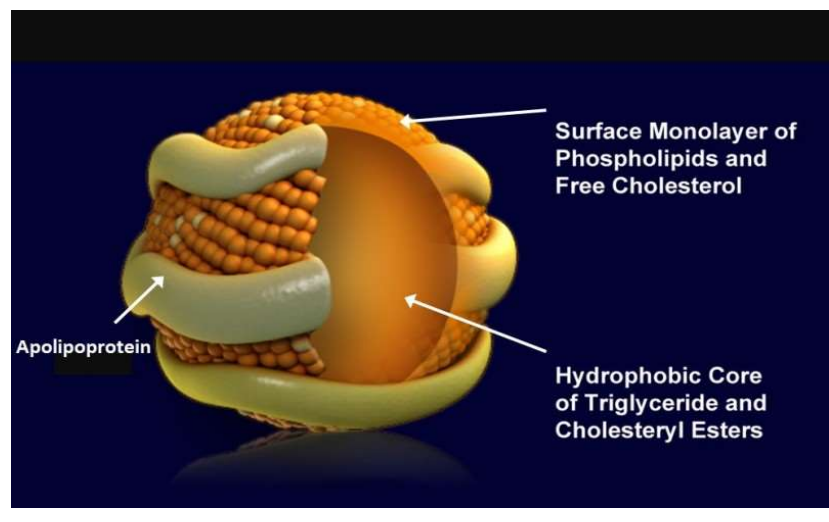

Figure 1. Lipoprotein Structure (figure modified from Biochemistry 39: 9763, 2000) seven classes based on size, lipid composition, and apolipoproteins.( Figure 2) [1]. 


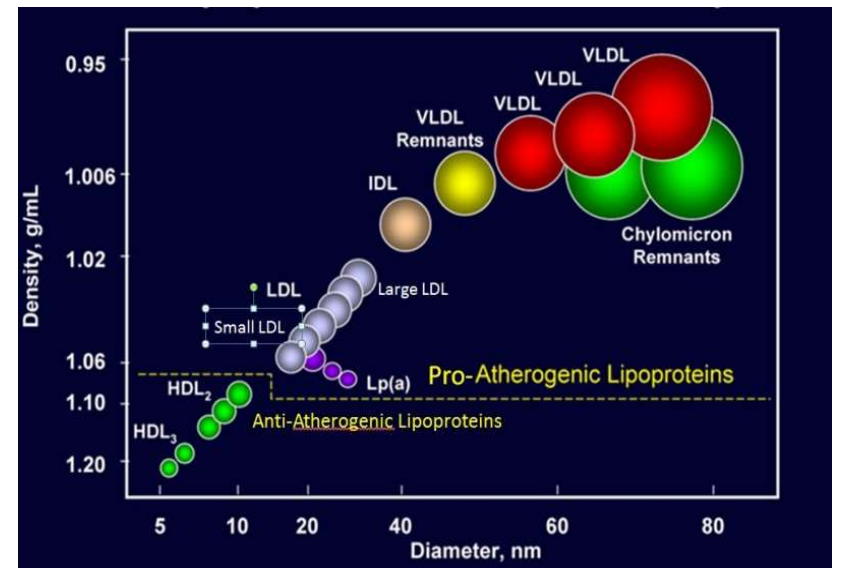

Figure 2. Classes of Lipoproteins (figure modified from Advances Protein Chemistry 45:303, 1994)

The problem of an inflammatory diseases of genitals, especially infections, which are sexually transmitted, annually grows. These diseases are one of the most widespread in the general structure of infectious pathology and bear serious medical, social and demographic danger.

The studying of the lipids exchange condition (LP) (Figure 6), thrombolic (Tr) link of a hemostasis and non-specific reactivity are of great importance for the course, development of complications and efficiency of inflammatory diseases treatment.(Figure 3)

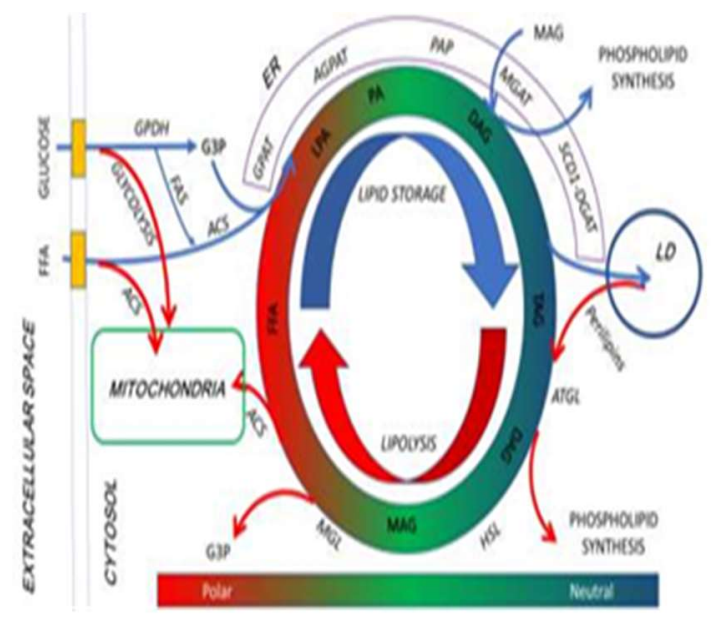

Figure 3. Overview of fatty acid metabolism.
During the immunoinflammatory processes there is LP imbalance which can be caused by an imbalance between about - and antioxidant systems [2]. In particular, the role of intracellular infectious agents was proved to take part in the development of dyslipoproteinemia (DLP) and atherosclerosis [3] (Figure 4).

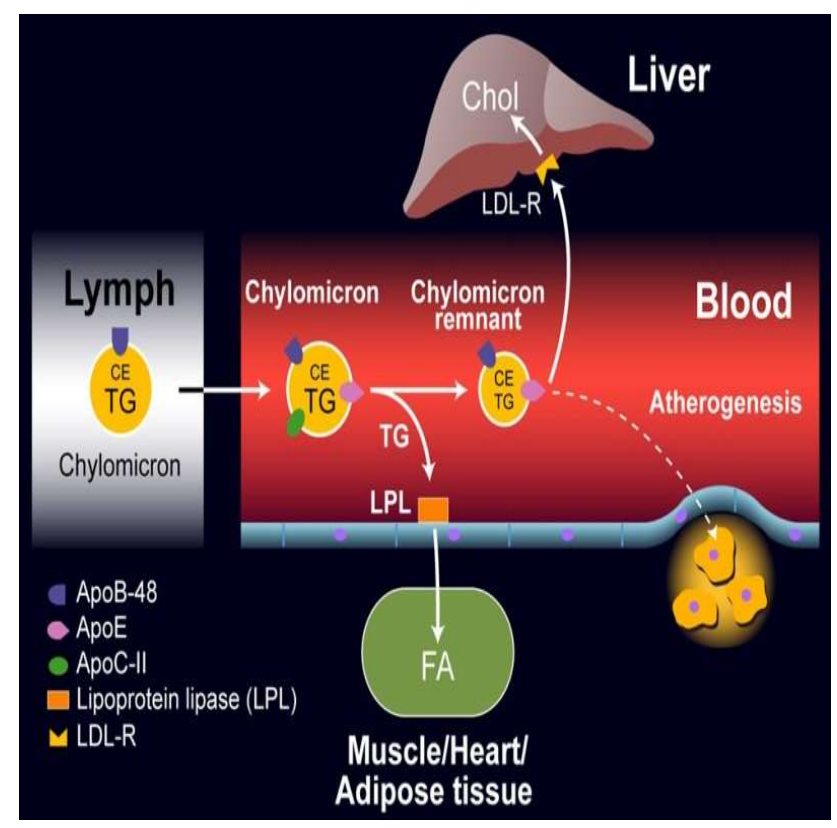

Figure 4. Exogenous Lipoprotein Pathway

For example, the chlamydias can change LP exchange in macrophages (Figure 5) at action of lipoproteins of the low density (LDL) that leads to formation of "spumous" cells. This fact, in its turn, promotes formation of atheromatous plaque, which are favorable environment for chlamydias and where they can survive and start immunopathological mechanisms [4]. The data on violations of LP of exchange, Tr link of hemostasis and also violation of system and local non-specific reactivity at patients with chronic non-specific inflammatory diseases of genitals are contradicting [5]. 


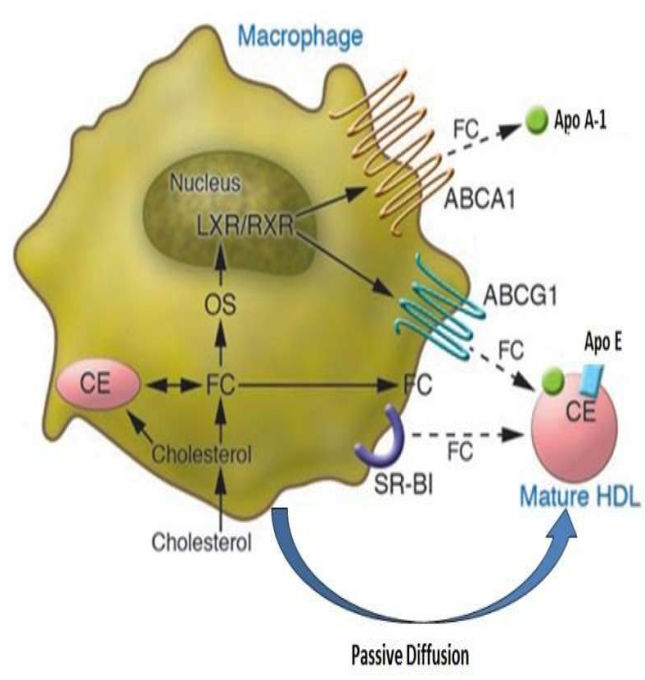

Figure 5. Cholesterol Efflux from Macrophages (modified from J. Clinical Investigation 116: 3090, 2006)

That's why we decided to carry out researches of LP exchange, a condition of Tr link of hemostasis and nonspecific reactivity at patients with chronic nonspecific inflammatory diseases of genitals [6].

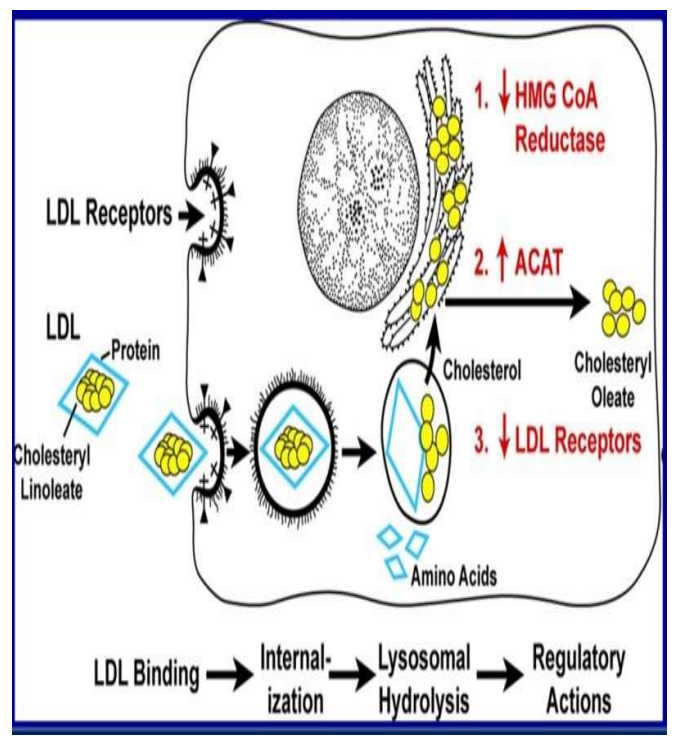

Figure 6. LDL Receptor Pathway (figure modified from Annual Review of Biochemistry 46: 897, 1977)

Scientific novelty of the received results: for the first time on the basis of clinical laboratory researches the intersections between the indicators of LP exchange, Tr link of hemostasis and nonspecific reactivity is proved in patients with chronic non-specific inflammatory diseases of genitals.

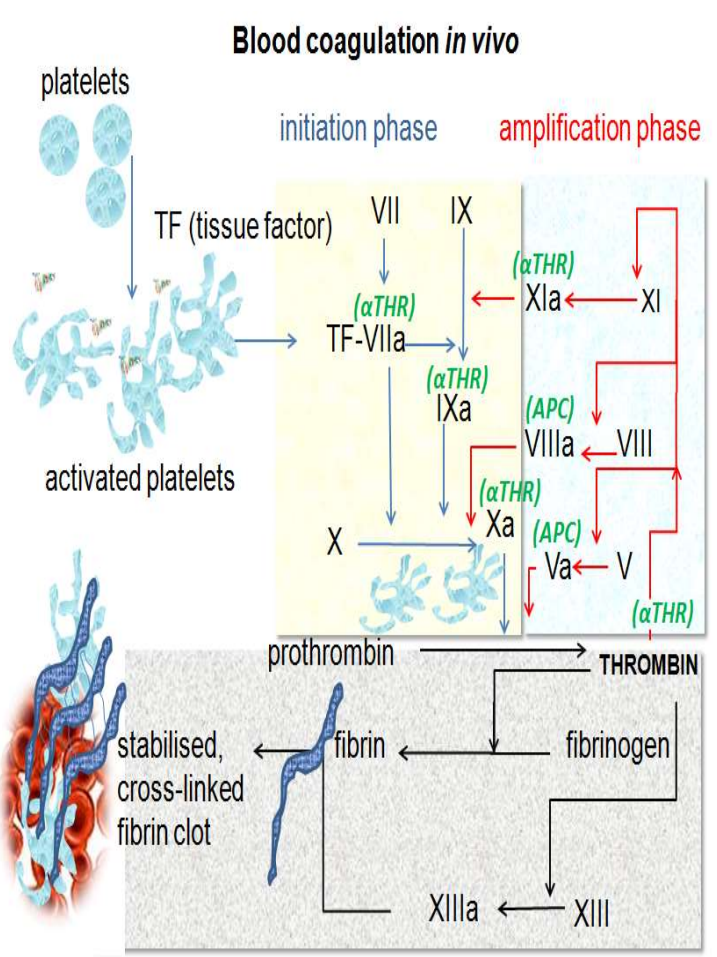

Figure 7. Blood coagulation in vivo

The growth of lipid indicators (total cholesterol, triglycerides, low density lipoprotein cholesterol, malondialdehyde) often occurs in clinically healthy individuals with age.

In recent decades, researchers have paid great attention to the process of inflammation and associated immune and non-immune mechanoses as one of the factors for the development and further progression of atherosclerosis [6]. Atherosclerosis is considered by them as an immune-inflammatory process that runs through the type of hypersensitivity reaction of the detained type, in which antigenic stimuli emanate from modified lipids [7,8]. 
That was also revealed data about the major role of leukocytes in atherogenesis and progression of coronary heart disease $[9,10]$. The production of active metabolites by leukocytes, their significant adhesion to the vascular endothelium and subsequent transdotal ulcer migration may be the beginning of the formation of an atherosclerotic plaque.

There is an oxidative modification of lipoproteins of nis-density. Against the background of hypercholesterolemia and dyslipidemia, autoaggression increases, and the level of circulating immune complexes increases. Modified low density lipoprotein overexpresses monocytic macrophages. They are a key proatherogenic factor. Absorption of low density lipoprotein by monocytes leads to the formation of "pony" cells, their accumulation in the walls of the vessels with subsequent necrosis, the formation of lipid bands, plaques, atherosum.

Consequently, dyslipidemia and elevated levels of low density lipoprotein cholesterol are considered to be a major risk factor for atherosclerotic inflammation.

Chronic immune fibrous inflammation is considered as an important factor in the development and progression of atherosclerosis and coronary disease against the background of elevated cholesterol levels of low density lipoprotein $[11,12]$.

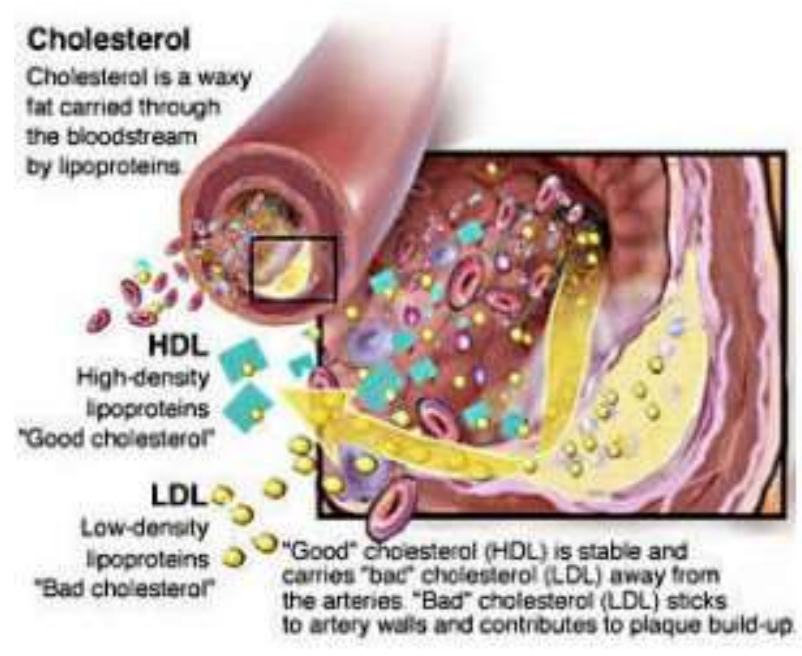

Figure 8. Elevated levels of cholesterol low-density lipoprotein as a major risk factor for atherosclerotic inflammation.

Many authors point to the ability of vitamin A to regulate lipid peroxidation processes. The presence of conjugate bonds in the vitamin A molecule and the propensity to auto-oxidation justify the possibility of its participation, the ability to reduce the activity of NADP and ascorbate-peroxidation in liver microsomes, inhibit microsomal lipid oxidation, and others [13].

The enhancement of phagocyte release of activated forms of oxygen (AFO) and its interaction with polyunsaturated fatty acids during inflammation activates peroxide lipid oxidation.

A certain low level of peroxide oxidation of lipids is necessary for the normal functioning of physiological systems [14]. It is supported by the balance of anti-and prooxidant systems. The positive influence of lipid peroxidation processes on a living organism is manifested by the restoration of composition and maintenance of 
the properties of biological membranes, of proteins, which includes thiol groups participation in energy processes, cell division, (cysteine, methionine, etc.). Antioxidants are synthesis of biologically active substances. Lipid able to inhibit free radical oxidation by binding acids in the blood of various lipids, which are free radicals and their transformation products transferred to the cells by specific transport [19].

proteins of apolipoproteins, form lipidtransporting protein macromolecules. Peroxide lipid oxidation occurs in the blood in the phase section: the aqueous medium - lipid in the lipids.

In low density lipoprotein, activated forms of oxygen are oxidized, mainly unsaturated fatty acids with different amounts of double bonds.

The antioxidant protection system (AOPS) is a collection of enzymatic and non-enzymatic factors that protect the cell from free radicals that have been formed [15].

Antioxidant enzymes include superoxide dismutase, which catalyzes oxygen dismutase into hydrogen peroxide, glutathione reductase, glutathione peroxidase, ceruloplasmin and catalase, which decomposes hydrogen peroxide into water and oxygen molecules [16,17].

The non-enzymatic system of AOPS includes fat-soluble ( $\alpha$-tocopherol, ubiquinone, naproquinone, carotenoids, creatinides, steroid hormones, including estrogens, etc.) and water soluble (sodium thiosulfate, glutathione, ascorbic acid, citric and nicotinic acid) substances [19]. Also among the natural antioxidants are a group

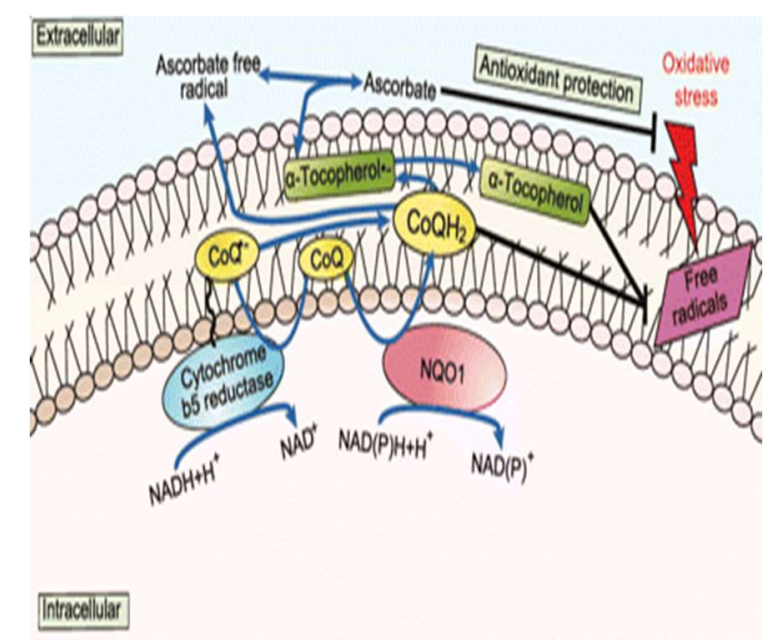

Figure 9. Antioxidant protection system (AOPS)

Catalase is a ferriferous hemoprotective enzyme responsible for catabolism of hydrogen peroxide [20].

Consequently, dyslipidemia and elevated levels of low density lipoprotein cholesterol are now considered as a major risk factor for atherosclerotic inflammatory complications.

Chronic immune fibrous inflammation is considered as an important factor in the development and progression of atherosclerosis and coronary disease against the background of elevated cholesterol levels of low density lipoprotein. 


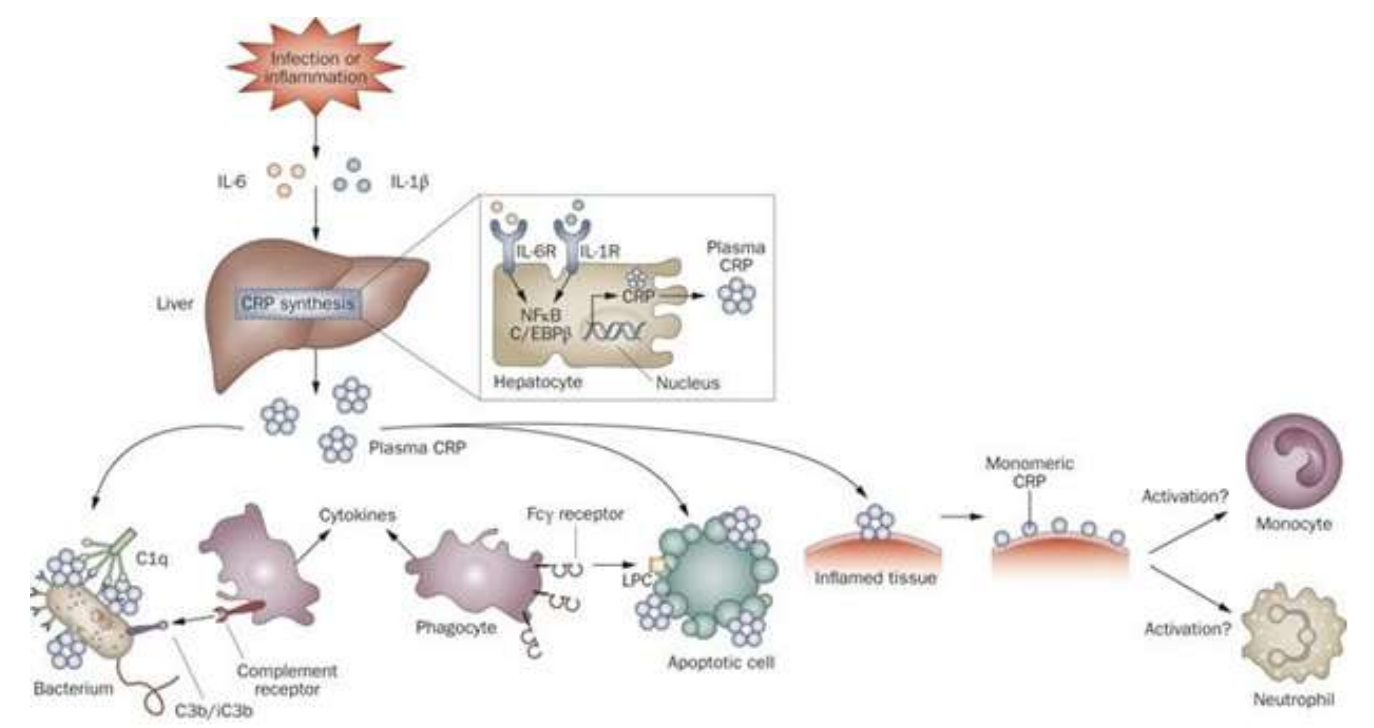

Figure 10. Free radicals and their transformation products

In our study, new pathogenetic aspects of the course of inflammatory diseases are established. It is shown that inflammatory process in genitals is followed by violations of exchange of LP: increase the content of cholesterol (CS), the CS LDL, decreas in concentration of the CS lipoproteins of the high density (LPHD), increase in level of triglycerides (TG), strengthening of the Lipid Peroxidation and also increase adhesive properties of $\operatorname{Tr}$ and decrease the level of the adhesive aggravativing factor of Willebrand (FW) (Figure 7), in plasma of patient's blood.

\section{Experimental part}

Material and methods

The object of research are the patients with chronic non-specific inflammatory diseases of genitals, exchange of LP, Tr link of hemostasis and non-specific reactivity in such patients.

Research methods - biochemical, hematologic, cytologic and statistical.
95 almost healthy people were examined - 50 men (M), and 45 women (W) of control group (C) and 162 patients with chronic non-specific inflammatory diseases of genitals aged 18-50 years underwent research. The clinical condition of patients was estimated on the basis of the anamnesis, survey of skin of genitals, at women - mucous vaginas by means of a gynecologic mirror (with dermatovenereologist of city hospital N 6, Zaporizhia, Lankina I.O.)

Bacterioscopic and cytologic researches were conducted with samples of scrapes from mucous membrane of the genitals painted by Romanovsky Gimz's method [V.V. Menshikov and co-authors, 1987]. Biochemical methods of the research were carried out in the accredited ZMAPO kliniko-diagnostic laboratory (the manager. - MD, prof. Yakushev V.S.).

The concentration of the general CS was determined by spectrophotometry method with the help of sets of reactants «Filisit Diagnostics», Dnipropetrovsk. Existence of 
chylomicrons (CM) and CS vLDL was determined by method of visual assessment of test after a blood plasma exposition at a temperature of $0^{\circ}-4^{\circ} \mathrm{C}$, concentration of the $\mathrm{CS}$ LDL by Burstein's method and Samay, concentration of the CS LPHD with the use of reactants of firm "Cormay", TG with the use of reactants of «Lachem», the Czech Republic. Verification of diagnoses concerning DLP was carried out according to medical recommendations about diagnosis of cardiovascular diseases [M.I. Lutay, 2003, D. Fredrikson, WHO, 1970].

Intensity the Lipid Peroxidation was estimated on concentration of MDA behind reaction with a tiobarbiture acid [A. I. Karpishchenko's, 1999].

For studying the condition of Tr link of hemostasis the reactions of adhesion, ADF aggregation and disaggregation of $\operatorname{Tr}$ of peripheral blood in $\operatorname{Tr}$ rich plasma were carried out [E.V. Mikhaylova 1986]. In patients with chronic non-specific inflammatory diseases of genitals the content of the FV vascular component was determined in plasma by the Evans et Osten method in O.A. Tsigulevo's modification [I.P. Baluda, etc. materials,

The general clinical blood test was made to all people: the quantity of erythrocytes, leukocytes, $\operatorname{Tr}$ in the calculating camera of Goryaev were counted, the concentration of hemoglobin was determined, as well as the leukogram by the unified method, defined ESR.
The morphological researches of cells of blood plasma were conducted in samples painted by Romanovsky Gimz's method [V.V. Menshikov ,1987]. For assessment of local system reactivity of an organism the complex of cytochemical indicators of leukocytes was used. Activity of myeloperoxidase (MT) that characterizes oxygen-dependenend mechanisms of phagocytosis was studied by a method of Graham-Knolle [V.V. Menshikov and, 1987], counted the average cytochemical rate (ACR). For assessment of activity of oxygendependened mechanisms the contents of the cationic proteins (CP) was studied by V.G. Shubich method. On the basis of leukogram's data and ESR of peripheral blood theintegrated indicators were counted with the help of mathematical formulas.

There were examined almost 95 healthy people - 50 men (M) and 45 women (W) aged 18-50 years and were distributed in groups: K1 (18-28 years) - $15 \mathrm{M}$ and 15W; K2 (29 -39 years) - $20 \mathrm{M}$ and 15W; K3 (40-50 years) - $15 \mathrm{M}$ and $15 \mathrm{~W} ; 162$ patients with chronic non-specific inflammatory diseases of genitals, in which the duration of a disease was 2-20 years and preliminary treatment was inefficient. Patients were also distributed in groups depending on age and gender. From 162 patients with chronic nonspecific inflammatory diseases of genitals 74 $\mathrm{M}$ and 88 -W were distributed: 18-28 years - the 60th patients (22 $\mathrm{M}$ and $38 \mathrm{~W}$ ), 29-39 years - 58 patients (30 $\mathrm{M}$ and $28 \mathrm{~W}), 40-50$ years - 44 patients (22 $\mathrm{M}$ and $22 \mathrm{~W})$. Depending on the 
anamnesis of life, the disease and data of clinical examination the patients were distributed in uniform groups. The examined patients (180 people) were also distributed in uniform groups depending on different types of activators of inflammatory process in diseases of genitals: the 1st group - patients with bacterial flora, 2 group - patients with trichomonads, the 3rd group - with fungal flora, a 4-a group - with a hlamidya, a 5th group - with virus and the 6th group with the mixed flora. Average age of patients in groups was $28.5-35.3$ years.
The statistical processing of variational series were carried out, defined criteria of reliability, using statistical criterion of " $\mathrm{t}$ " of $\mathrm{St}^{6}$ yudent for two inconnected developments and for developments from in pairs connected options. Correlations analysis was used for numerical characteristics of the connection between different parameters. Calculations were made using Excel and Statistics Packages. We examined 180 patients.

Table 1. Correlation coefficients of lipid metabolism, platelet count and haemostasis relative to the Willebrand factor in patients with chronic non-specific inflammatory diseases of genital organs

\begin{tabular}{|c|c|c|c|c|}
\hline Indicator, unit of measurements & $\begin{array}{c}\text { Quantity of } \\
\text { Tr.1 - }\end{array}$ & $\begin{array}{c}\text { Of the } \\
\text { beginning of } \\
\text { ADF of } \\
\text { aggregation }\end{array}$ & $\begin{array}{c}\text { Intensity of the } \\
\text { maximum } \\
\text { aggregation of } \\
\text { Tr\% } \%\end{array}$ & $\begin{array}{c}\text { Relative contents } \\
\text { of FW, \% }\end{array}$ \\
\hline Level is CS HDLP, mmol. 1-1 & $-0,73^{*}$ & $-0,52^{*}$ & 0,48 & $-0,52^{*}$ \\
\hline Concentration of CS, mmol. 1 - 1 & $-0,61^{*}$ & $-0,74^{*}$ & $0,89 *$ & $-0,86^{*}$ \\
\hline $\begin{array}{c}\text { Concentration the CS LDLP, } \\
\text { mmol. 1 - }\end{array}$ & $0,73^{*}$ & $0,51^{*}$ & $-0,63^{*}$ & $0,64^{*}$ \\
\hline
\end{tabular}

Note. ${ }^{*}-r<0.05$ in comparison with control

\section{Results and discussion}

Thus, the study of the correlation between the indices of the exchange of LP and Tr hemostasis, non-specific reactivity in patients with chronic non-specific inflammatory diseases of genitals showed that the increase in atherogenic propertis of blood plasma correlated with increased activity of the blood transfusion linkage and damage to the vascular endothelium
These changes took place in parallel with the advantage of the Mo-macrophage system of the phagocytosis system against the background of reduced phagocytic activity of circulating neutrophils and the advantage of the cellular mechanism of specific protection, the developmentof endogenous intoxication. 


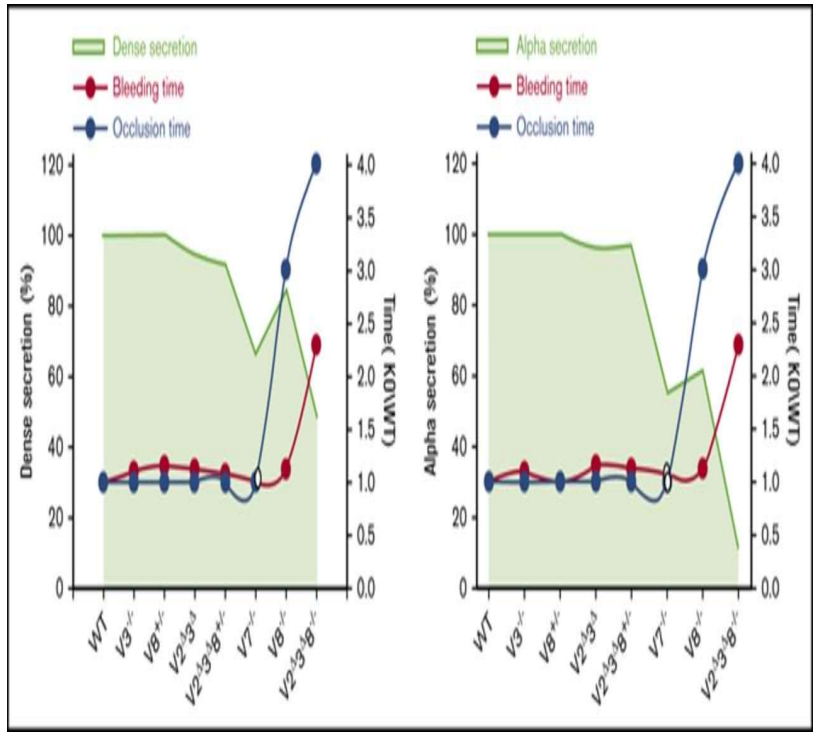

Figure 11. An increase in the atherogenic properties of blood plasma correlates with an increase in the activity of blood transfusion and damage to the vascular endothelium

\section{Conclusions}

The article presents the theoretical substantiation and a new solution to the scientific problem aimed at identifying the nature of the disorders of LP, Tr, hemostasis and non-specific reactivity in patients with chronic non-specific inflammatory diseases of genitals .

1. In patients with chronic non-specific inflammatory diseases of genitals, violations of LP have been established: in women of the third senior age group, an increase in the concentration of general CS was detected 1.2 times; in patients of both genders, an increase in the incidence of CM-emia in the second and third groups ( 9 out of 58 and 10 of 44 ), the presence of cholesterol LDL cholesterol (14 out of 58 and 22 of 44) compared with $\mathrm{K}$, an increase in $\mathrm{TG}$ concentration in 1,3 times, MDA in 1,6 times, in the older group of patients in women - an increase in the level of LDL cholesterol in 1, 4 times and a decrease in the level of cholesterol HDL in 1.4 times $(\mathrm{p}<0.05)$. CM-emia was found more frequently in patients with fungal (11 out of 50 ) and mixed (10 of 41) flora, LDL cholesterol levels were significantly lower in patients with trichomonads, fungal and mixed flora, and the level of LDL-C was increased in patients of all groups on average in 1,6 times. GCS was more frequent (23 out of 30 ) in the middle-aged and half-men group with trichomonadal, viral and mixed flora $(p<0,05)$ compared to other groups (one third of patients). GHS with high levels of cholesterol was most often found in patients with chlamydia.

2. In patients with chronic non-specific inflammatory diseases of genitals, the total frequency of DLP with high risk of atherogenesis increased in accordance with age: in the younger group, 15 out of 60 cases were detected, in the middle group - 25 out of 58, and older than 26 in $44(\mathrm{p}<0.05)$. DLP type IIa was more common in younger ( 7 out of 22) and middle (11 out of 30) groups compared to the older (3 out of 22) group $(\mathrm{p}<0,05)$ and in patients with chlamydial ( 7 out of 28) and viral an infection (5 out of 19) ( $p$ $<0,05$ ), in comparison with patients of other groups.

3. In the examined patients, changes in $\operatorname{Tr}$ activity were observed: the growth of adhesion of $\mathrm{Tr}$ in the men of the middle group was 1.2 times and in the women of the elder group by 1.4 times, the maximum ADP aggregation in all groups of patients was 1.9 times, the reduction of the time 
of the beginning of ADP- aggregation in men of junior and middle groups in 1,7 times and in women of middle and senior groups in 1,5 times, decrease in the level of PV (30 - 62\%) from such in $\mathrm{K}(100 \%)(\mathrm{p}<0,05)$ in patients with chlamydial infection.

4. It was found that in all groups of examined patients, the percentage of rodenuclear neutrophils increased in 2 times $(p<0,05)$. The total analysis of violations of the integrative indicators of leukograms and ESR peripheral blood (IZL, ILHSOE, ILG, SI, ISNL, ISNM, ISLM, ISLM), as well as cytochemical indicators of functional activity of leukocytes in patients, indicated a violation of non-specific protective mechanisms, the advantage of the macrophage component in mechanisms of phagocytosis, as well as cellular mechanisms of specific protection, propensity for autointoxication and hypersensitivity reactions of immediate type.

5. To prevent the development of severe inflammatory processes and their complications in the form of atherogenic DLP, violations of the Tr link of blood clotting, as well as to increase the effectiveness of pharmacotherapy in patients with COCs, it is suggested to carefully monitor the indices of LP, LPA, adhesion and aggregation functions of $\operatorname{Tr}$ and level the relative content of $\mathrm{PV}$, become the general reactivity of the organism, and, if necessary, use the means of its correction.

6. The combined data of the correlation analysis suggest that the growth of atherogenic properties of blood plasma of patients with COCs occurred in accordance with the growth of adhesive and aggregation properties of $\mathrm{Tr}$ and vascular endothelium damage. These disorders occur in parallel with the advantage of Momacrophageal phagocytosis against the backdrop of reduced activity of neutrophils and cellular mechanisms of immunopathological reactions.

It has been stated that indices changes of lipid exchange and increasing of lipid peroxidation are accompanied by the inflammatory process, which show the increase of proatherogenic blood characteristics.

Rate increase of dislipoproteinlysis determination, including dislipoproteinlysis with high atherogenity depended upon the patients age.

Patients with chlamydiosis revealed the highest atherogenesis risk taking into consideration ethiological factor of genitals inflammation.

The increase of adhesive-aggregative thrombocytes properties testified to more intensive thromb's formation in patients with chronic genitals inflammatory diseases.

In patients with chronic non-specific inflammatory diseases of genitals disordes of non-specific protective mechanisms prevalence of macrophagol component in phagocytosis mechanisms, increasing of disposition to autointoxication and reaction of hypersensitivity of immediate type are revealed after full blood count index and total analysis change of 
cytochemical and integral leukogdramm indices and peripheral blood ESR.

On the basis of coorelative analyses results one can conclude that the increase of atherogenic properties of blood plasma in patients with chronic non-specific inflammatory diseases of genitals took place in accordance with vascular endothelium damage.

The thesis is the first to show the effectiveness of complex treatment of different atherosclerotic pathogenesis links by means of correction of proatherogenic lipid fractions and antioxidative complexes

\section{References}

[1] Introduction to Lipids and Lipoproteins Kenneth R Feingold, MD and Carl Grunfeld, MD,PhD:https://www.ncbi.nlm.nih.gov/books/NBK3058 96/\#top

[2] Mavrov G.I., Unuchko S.V., Bondarenko G.M., Dermatology and Venereology; 2004, pp.67-71.

[3] Abu Ebeyn Ahmad Mohamed Clinicoimmunological and pharmacological aspects in the local treatment of chronic prostatitis. Urology; 2003, pp.66-68.

[4] Mavrov GI, Belozerov AP. Dermatology and Venereology 2003; Rudyk YuS. Dermatology and Venereology 2005:16-18.

[5] Feingold KR, Grunfeld C. Lipids: a key player in the battle between the host and microorganisms. Journal of lipid research. 2012 Dec;53(12):2487-9. PubMed PMID: 23075464. Pubmed Central PMCID: 3494250 .

[6] Schmidt K, Noureen A, Kronenberg F, Utermann G. Structure, function, and genetics of lipoprotein (a). Journal of lipid research. 2016 Aug;57(8):1339-59. PubMed PMID: 27074913. Pubmed Central PMCID: 4959873.
[7] Van de Sluis B, Wijers M, Herz J. News on the molecular regulation and function of hepatic lowdensity lipoprotein receptor and LDLR-related protein 1. Current opinion in lipidology. 2017 Jun;28(3):241-7. PubMed PMID: 28301372. Pubmed Central PMCID: 5482905.

[8] Ilyenko L.N., Ivanova E.V. Evaluation of the effectiveness of the use of the drug Enterosgel in the complex treatment of recurrent forms of nonspecific vaginitis. Art of treatment; 2014, pp.84-85.

[9] Beregova O.G., Krivohac'kayaY.O., Lankina I.O., Dolgopolova I.A., Elizarova L.I. Laboratory general clinical and microcytoscopic examination for the disease of female genital organs and mammary gland. Educational and methodical manual, Zaporizhzhzya; 2006, pp.164-165

[10] Titov V.N., Lysicin D.M., Amelushkina D.M, Double bonds of fatty acids, alcohols, glycerin, cholesterol and non-polar serum lipids. Diagnostic value of hypercholesterolemia; 2012, pp.7-11.

[11] Neubauer R.A. Free radicals and antioxidants, Lancet; 1994, pp.1440-1441.

[12] Garvey E.P. E.P. Garvey, J.A. Oplinger, E.S. Furfine is a slow, tight binding, and highly selective inhibitor of inducible nitric-oxide synthase in vitro and in vivo; 1997, pp. 4959-4963.

[13] Yin G, Wang Y, Cen X, Yang M, Liang Y, Xie Q. Lipid Peroxidation-Mediated Inflammation Promotes Cell Apoptosis through Activation of NF- $\kappa$ B Pathway in Rheumatoid Arthritis Synovial Cells. Mediators of Inflammation 2015;2015:1-10.

[14] Orosz C.G. Endothelial activation and chronic allograft rejection, Clin. Transplant; 2014, pp.299-303.

[15] Ambunin V.G., Zakharin A.K., Conjugation of changes in catecholamines, thiol compounds and lipid peroxidation in bronchial asthma; 2011, pp.63-66.

[16] Savchenko R.P., Gordyushina I.V., Effect of oxidative stress on platelet activation in patients with renal pathology; 2004, pp.48-51. 
[17] Suvorov A.P., Correction of violations of antioxidant protection in chronic prostatitis by millimeterwave electromagnetic radiation; 2001, pp.39-41.

[18] Kondakova A.P.. Intensity of the processes of lymphocyte membrane lipid peroxidation and oxidative modification of plasma proteins in patients with urogenital chlamydiosis; 2014, pp.24-28.

[19] Moore, K.J.,Tabas, I. Macrophages in the pathogenesis of atherosclerosis. Cell 145; 2011, pp. 341355.

[20] Vizir VA, Makurina GI. State of free-radical processes and antioxidant defence of patients with psoriasis and concomitant essential hypertension. Zaporozhye Medical Journal. 2016(4):21-8. 